\title{
Mineral resources in life cycle impact assessment—part I: a critical review of existing methods
}

\author{
Thomas Sonderegger $^{1}$ (D) $\cdot$ Markus Berger $^{2} \cdot$ Rodrigo Alvarenga $^{3} \cdot$ Vanessa Bach $^{2} \cdot$ Alexander Cimprich $^{4} \cdot$ Jo Dewulf $^{3}$. \\ Rolf Frischknecht ${ }^{5}$. Jeroen Guinée ${ }^{6} \cdot$ Christoph Helbig $^{7} \cdot$ Tom Huppertz $^{8}$. Olivier Jolliet ${ }^{9}$ - Masaharu Motoshita ${ }^{10}$. \\ Stephen Northey ${ }^{11}$. Benedetto Rugani ${ }^{12}$. Dieuwertje Schrijvers ${ }^{13,14} \cdot$ Rita Schulze $^{6}$. Guido Sonnemann ${ }^{13,14}$. \\ Alicia Valero $^{15} \cdot$ Bo P. Weidema ${ }^{16} \cdot$ Steven B. Young ${ }^{4}$
}

Received: 29 March 2019 / Accepted: 16 January 2020 / Published online: 4 February 2020

(C) Springer-Verlag GmbH Germany, part of Springer Nature 2020

\begin{abstract}
Purpose The safeguard subject of the Area of Protection "natural Resources," particularly regarding mineral resources, has long been debated. Consequently, a variety of life cycle impact assessment methods based on different concepts are available. The Life Cycle Initiative, hosted by the UN Environment, established an expert task force on "Mineral Resources" to review existing methods (this article) and provide guidance for application-dependent use of the methods and recommendations for further methodological development (Berger et al. in Int J Life Cycle Assess, 2020).

Methods Starting in 2017, the task force developed a white paper, which served as its main input to a SETAC Pellston Workshop ${ }^{\circledR}$ in June 2018, in which a sub-group of the task force members developed recommendations for assessing impacts of mineral resource use in LCA. This article, based mainly on the white paper and pre-workshop discussions, presents a thorough review of 27 different life cycle impact assessment methods for mineral resource use in the "natural resources" area of protection. The methods are categorized according to their basic impact mechanisms, described and compared, and assessed against a comprehensive set of criteria.
\end{abstract}

Responsible editor: Andrea J Russell-Vaccari

Electronic supplementary material The online version of this article (https://doi.org/10.1007/s11367-020-01736-6) contains supplementary material, which is available to authorized users.

Thomas Sonderegger sonderegger@ifu.baug.ethz.ch

1 Chair of Ecological Systems Design, Institute of Environmental Engineering, ETH Zurich, John-von-Neumann-Weg 9, 8093 Zurich, Switzerland

2 Chair of Sustainable Engineering, Technische Universität Berlin, Office Z1, Straße des 17. Juni 135, 10623 Berlin, Germany

3 Department of Sustainable Organic Chemistry and Technology, Ghent University, Coupure Links 653, 9000 Ghent, Belgium

4 School of Environment, Enterprise and Development, University of Waterloo, 200 University Avenue West, Waterloo, Ontario N2L 3G1, Canada

5 treeze Ltd., Kanzleistrasse 4, 8610 Uster, Switzerland

6 Institute of Environmental Sciences (CML), Department of Industrial Ecology, Leiden University, Einsteinweg 2, 2333 CC Leiden, The Netherlands

7 Resource Lab, University of Augsburg, Universitaetsstraße 16, 86159 Augsburg, Germany

8 RDC Environment, 57 Avenue Gustave Demey, 1160 Brussels, Belgium

9 School of Public Health, Environmental Health Sciences, University of Michigan, Ann Arbor, MI, USA

10 Institute of Science for Safety and Sustainability, National Institute of Advanced Industrial Science and Technology,

Tsukuba, Ibaraki 305-8569, Japan

11 Department of Civil Engineering, Monash University, Clayton, VIC, Australia

12 Environmental Research \& Innovation (ERIN) department, Luxembourg Institute of Science and Technology (LIST), 41 Rue du Brill, L-4422 Belvaux, Luxembourg

13 University Bordeaux, ISM, UMR 5255, Talence, France

14 CNRS, ISM, UMR 5255, Talence, France

15 CIRCE Institute - Universidad de Zaragoza, Mariano Esquillor Gómez, 15, 50018 Zaragoza, Spain

16 Danish Centre for Environmental Assessment, Aalborg University, Rendsburggade 14, 9000 Aalborg, Denmark 
Results and discussion Four method categories have been identified and their underlying concepts are described based on existing literature: depletion methods, future efforts methods, thermodynamic accounting methods, and supply risk methods. While we consider depletion and future efforts methods more "traditional" life cycle impact assessment methods, thermodynamic accounting and supply risk methods are rather providing complementary information. Within each method category, differences between methods are discussed in detail, which allows for further sub-categorization and better understanding of what the methods actually assess.

Conclusions We provide a thorough review of existing life cycle impact assessment methods addressing impacts of mineral resource use, covering a broad overview of basic impact mechanisms to a detailed discussion of method-specific modeling. This supports a better understanding of what the methods actually assess and highlights their strengths and limitations. Building on these insights, Berger et al. (Int J Life Cycle Assess, 2020) provide recommendations for application-dependent use of the methods, along with recommendations for further methodological development.

Keywords Life cycle assessment $\cdot$ Life cycle impact assessment $\cdot$ Method review $\cdot$ Mineral resources $\cdot$ Raw materials $\cdot$ Resource depletion · Life Cycle Initiative · Task force mineral resources

\section{Introduction}

Mineral resources - defined here as chemical elements (e.g., copper), minerals (e.g., gypsum), and aggregates (e.g., sand) as embedded in a natural or anthropogenic stock, that can hold value for humans to be made use of in the technosphere (Berger et al. (2020)) - are of great relevance for industry and society. Environmental impacts associated with mineral resource extraction are assessed in relatively well-established life cycle impact assessment (LCIA) categories, e.g., climate change or acidification (see e.g. Nuss and Eckelman 2014). However, how to assess other impacts of mineral resource use as such - e.g., whether in terms of the availability of these resources for future generations or in terms of shorter-term risks of supply-chain disruptions - has been a subject of persistent debate (see e.g. Dewulf et al. 2015; Drielsma et al. 2016b) and a variety of LCIA methods based on different concepts are available (see e.g. Sonderegger et al. 2017). It is still discussed what the safeguard subject of the area of protection (AoP) "natural resources" should be (Sonderegger et al. 2017; Berger et al. 2020). It is even questioned whether an impact assessment of mineral resource use - that by definition comprises environmental and economic aspects - is in the scope of an environmental LCA at all (Drielsma et al. 2016b). It might be due to the ambiguity on what actually should be protected with regard to mineral resources in LCA that various impact pathways are currently modeled, assessing different consequences of mineral resource use, e.g., the depletion of reserves, increased efforts for future extraction, or short-term supply risks. Furthermore, often inadequate methods are applied in LCA practice, providing the "right" answer to the "wrong" question: e.g., methods assessing the long-term depletion of mineral resources in the earth's crust are mistakenly used by LCA practitioners who are actually interested in the short-term economic risks of raw material supply disruptions (Fraunhofer 2018).

To address these challenges, the Life Cycle Initiative, hosted by the UN Environment, established an expert task force on "Mineral Resources" within its broader project on "Global Guidance for LCIA Indicators". The output of the task force is presented in this review of existing methods, which also served as basis for a recommendations paper (Berger et al. 2020). This review paper describes the task force and its working process, gives an overview of reviewed methods and their impact mechanisms, categorizes and describes the methods in detail, assesses them based on an assessment scheme, and finally discusses their strengths and limitations. The aim is to describe and compare methods with regard to their methodological approaches in order to better understand what the methods actually assess.

\section{The task force}

The task force comprised 62 members from academia, the metals and mining industry, other industries, geological departments, consulting, and Life Cycle Inventory (LCI) database providers, representing 14 countries around the globe. Twenty-three members ( 17 from academia, among them many method developers, 4 from consulting, 1 from the metals and mining industry, 1 from oil and gas industry) have been "active" members, participating in calls, working in sub-groups, and finally contributing to the scientific publications. The task force commenced in the beginning of 2017. Based on discussions in regular online meetings, the task force developed a white paper, which served as the main input to a SETAC Pellston Workshop ${ }^{\circledR}$ in June 2018. In this workshop, a subgroup of 8 of the task force members with complementary backgrounds and expertise ( 5 from academia, 2 from consulting, 1 from oil and gas industry) agreed on recommendations. This review paper is mainly based on the white paper and the pre-workshop discussions whereas the recommendations paper (Berger et al. 2020) mainly presents the workshop discussions and output. 


\section{Material flow and impact mechanism overview}

At the time the task force started its work, 33 methods assessing impacts of mineral resource use were available from literature or provided to the task force internally by method developers. For those methods with methodological differences between an old and an updated version, e.g., anthropogenic stock extended abiotic depletion potential method (AADP) or EDIP, we reviewed both in order to cover all the different approaches. For the other methods, we only considered the most recent version, e.g., LIME. This resulted in a set of 27 different methodological approaches. We first identified their basic impact mechanisms and related these to flows of mineral resources from the lithosphere through the technosphere and finally back into the ecosphere (Fig. 1).

The material flow layer (gray layer in Fig. 1) shows that primary/natural mineral resources are extracted from natural stocks in the lithosphere (a part of the ecosphere) and enter the technosphere via mining and quarrying, further on just called mining. Mineral resources are immobilized in products and infrastructure (collectively termed "in-use stocks") for short to long time scales (e.g., aluminum can vs. steel bridge) and at different qualities. By means of recycling, mineral resources can be kept and cycled inside the technosphere for different time scales and at different qualities (up- or down-cycling). If products are not recycled, mineral resources can be stored at different qualities in disposal stocks, e.g., landfill stocks, from which they potentially may be recovered. The quality of an abiotic resource may be a complex composite of different quality aspects. With regard to the efforts needed to extract a resource from a natural mineral deposit, this might for example include target element grade, "gangue minerals" or impurity grades, grain size distributions and grain "texture", ore hardness, size and heterogeneity of the deposit, or accessibility (e.g., depth, remoteness). Conceptually, many of these aspects may be applicable to extraction from anthropogenic stocks with some tweaking. The anthropogenic stock in the technosphere (product + disposal stocks) is the source for secondary/anthropogenic mineral resources. Therefore, it is argued that an actual loss of mineral resources for human use only occurs through dissipation, i.e., any form of use rendering a mineral resource unrecoverable, whether in the ecosphere or in the technosphere. For further discussion of the dissipation concept, see Berger et al. (2020). (Supplementary Material 1 (section S2) further describes and details mineral resource quality, dissipation, and the ecosphere-technosphere boundaries.)

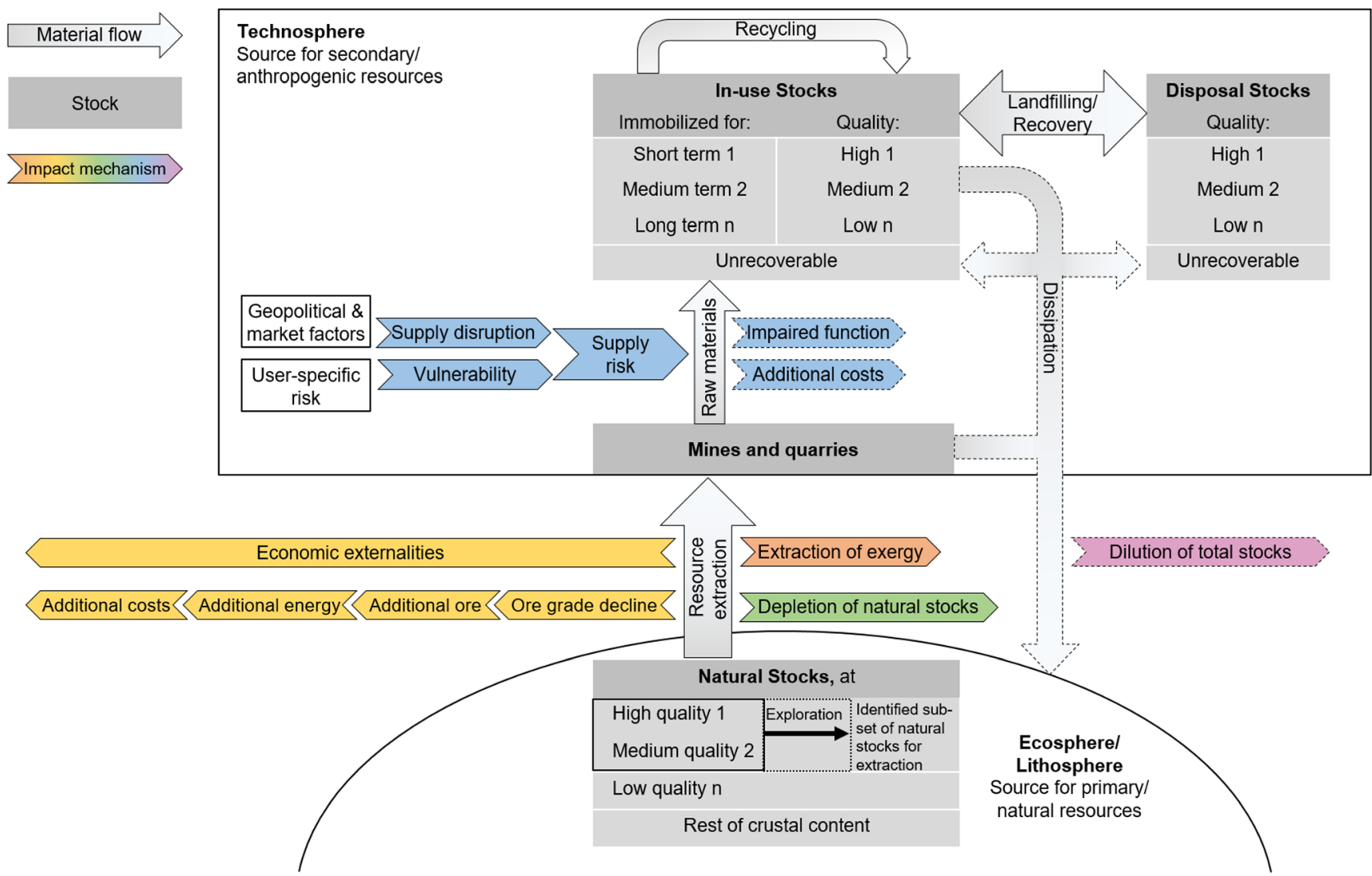

Fig. 1 Material flow (gray layer) and impact mechanism overview, presented in color for depletion methods (green), future effort methods (yellow), thermodynamic accounting methods (orange), supply risk methods (blue), and the "dilution of total stocks" approach (purple). Dashed material flows and impact pathways are proposed or discussed but not agreed, operational, or published yet 
On top of the material flow layer, an impact mechanism layer (colored layer in Fig. 1) has been added to show the position of characterization models in the material flow context. Starting from mineral resource extraction, some methods model the depletion of natural stocks (in one case also considering the anthropogenic stock) (in green), others the extraction of exergy (i.e., the exergy difference between the mineral resource as found in nature and a defined reference state in the natural environment) (in orange), and still others an ore grade decline and resulting additional ore requirements, energy, or costs (in yellow). Other methods do not consider physical parameters but directly model economic externalities, i.e., costs or welfare loss for future generations (also in yellow). Another category of methods (in blue) models the supply risk of mineral resources/raw materials in the technosphere, taking into account the probability of supply disruption resulting from geopolitical and market factors (e.g., production concentration and political instability of producing countries) as well as the vulnerability of a user to supply disruptions. These methods have conceptualized, but not yet operationalized, the "endpoints" of supply risk as impaired product functions and additional costs of production. The "dilution of total stocks" approach, as suggested by van Oers et al. (2002) and van Oers and Guinée (2016), is also still in its conceptual stage of development (in purple). The approach assumes that only dissipation into the ecosphere constitutes an absolute loss, not taking dissipation within the technosphere into account. Therefore, the arrow in Fig. 1 starts at the dissipation flow into the ecosphere (as other methods start from primary mineral resource extraction). Furthermore, the approach considers the total stock, i.e., the natural and the anthropogenic stock.

Based on the main impact mechanisms illustrated in Fig. 1, methods were categorized into four categories: depletion, future efforts, thermodynamic accounting, and supply risk methods (Fig. 2). This categorization is in line with those of previous literature (see e.g. Stewart and Weidema 2005; Steen 2006; Rørbech et al. 2014; Swart et al. 2015) adding the "supply risk" category. Since the "dilution of total stocks" approach is not yet operational, it is not considered in this categorization but further discussed in Berger et al. (2020). The grouping within a category is explained in the corresponding category subsections (4.1-4.4). A special case is the thermodynamic rarity approach, which can be assigned to two categories. On the one hand, it includes typical elements of thermodynamic accounting; i.e., it accounts for exergy extraction assessed as the exergy difference between a mineral resource as found in nature (e.g., copper in the ore) and a defined reference state (see Section 4.3). On the other hand, by assessing the cumulative exergy that would be needed to reconcentrate a mineral from crustal concentration to mine concentration, it also considers hypothetical future efforts. The methods are discussed by category in the following section.

\section{Description of methods}

The discussion of methods is organized into four subsections following the four method categories: depletion, future efforts, thermodynamic accounting, and supply risk methods. In each section, methods are shortly presented and some method category-specific assumptions and challenges are discussed.

\subsection{Depletion methods}

The depletion concept is related to the reduction of a certain stock (or a set of stocks). This concept is often used as a proxy for the availability of mineral resources: it is assumed that the extraction of mineral resources from the ecosphere, i.e., the reduction of the natural stock, renders the mineral resources less available. The characterization models of the ADP
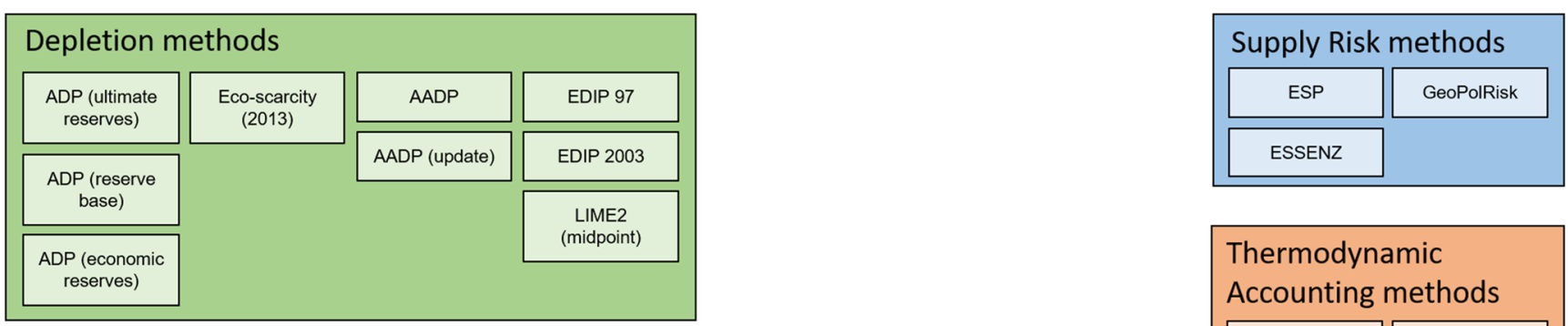

Future Efforts methods
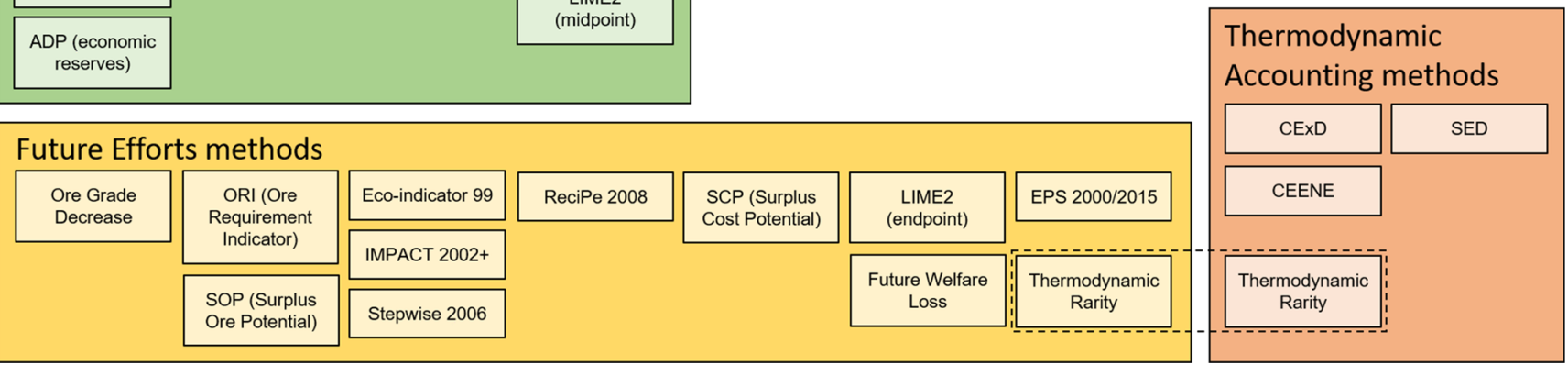

Fig. 2 Overview of method categorization according to underlying impact mechanisms; the thermodynamic rarity approach has elements of two categories 
(abiotic depletion potential) method family are based on the ratio between the annual extraction of mineral resources and the square of a natural stock estimate (Guinée and Heijungs 1995). Members of the ADP method family include the Swiss Ecological Scarcity method (eco-scarcity) (Frischknecht and Büsser Knöpfel 2013), based on $\mathrm{ADP}_{\text {economic reserves, }}$ and the AADP method (Schneider et al. 2011, 2015).

The variations of the ADP methods can be classified according to the stock estimate used in the model, i.e., $\mathrm{ADP}_{\text {ultimate reserves, }} \mathrm{ADP}_{\text {reserve base, }}$, and $\mathrm{ADP}_{\text {economic reserves }}$ (the former is based on crustal content estimates, the latter two on US Geological Survey (USGS) estimates (USGS 2010)). The choice of stock estimate has implications on what is actually assessed by the model and has been extensively debated (see e.g. Guinée and Heijungs 1995; Hauschild and Wenzel 1998; van Oers et al. 2002; Drielsma et al. 2016a; Sonderegger et al. 2017; and the discussion section). The eco-scarcity method theoretically embeds the $\mathrm{ADP}_{\text {economic re- }}$ serves model in the method's distance-to-target approach, i.e., comparing current extraction rates with (politically defined) target rates, but does not modify the model as such. The AADP method considers that mineral resources may still be available after extraction from natural stocks as they are stored in anthropogenic stocks (e.g., electronic devices/waste). The characterization model therefore uses the sum of the natural stock (USGS resources (see Table S1) in the original version and ultimate reserves in the updated version) and the anthropogenic stock in the denominator. However, the mineral resource extraction rate in the numerator considers only extraction from natural stocks and not from anthropogenic stocks.

Other depletion methods include EDIP 1997 and 2003 (Wenzel et al. 1997; Hauschild and Potting 2005) and LIME $2_{\text {midpoint }}$ (Itsubo and Inaba 2012). The EDIP and LIME2 $2_{\text {midpoint }}$ methods do not use the annual extraction to stock ratio but only the inverse of natural stock estimates (economic reserves in both cases). They might therefore not be depletion methods in a strict sense, though they are closely related. The argument for this approach is that the integration of current annual production into the indicator may underestimate future risks of mineral supply shortages for minerals that are not yet used in large volumes.

\subsection{Future efforts methods}

Future efforts methods may be generalized as seeking to assess the consequences of current mineral resource use on societal efforts to extract a unit of mineral resource in the future. Ultimately, the use of a specific unit of mineral resource is implying a change in availability to future users of that very unit of mineral resource. This requires future users either to reuse the same unit of the mineral resource (now at a different quality), to use another unit of mineral resource, or to use another technology (Figure S3). It is important to note that the use of the future mineral resource or technology can be less impacting and less expensive than the original use, in which case there is no negative impact on future users from current dissipation (Stewart and Weidema 2005).

Most existing future efforts methods are based on the assumption that ore grades mined in the future will be lower (see Supplementary Material 1, section 3.1) and apply various proxy indicators to assess the related assumed increases in costs, e.g., surplus ore to be dealt with, surplus energy use, or surplus costs (see Table S2 for a list of all methods and their underlying modeling). The methods can be grouped into different subcategories according to what they include in their impact pathway.

Ore grade only methods These methods focus on ore grades only without modeling any future efforts (they could therefore also be classified as depletion methods, using ore grades as the indicator). For this review, they are considered a proxy for potential future costs. Methods in this subcategory include the ore requirement indicator (ORI) method (Swart and Dewulf 2013), the ore grade decrease method (Vieira et al. 2012), and the surplus ore potential (SOP) method (Vieira et al. 2016a; Vieira 2018).

Ore grade-surplus energy methods These methods are based on the approach by Müller-Wenk (1998), which uses gradetonnage relationships based on assumed frequency distribution of concentrations in the earth's crust (see p. 78 in Goedkoop and Spriensma (2001) for a discussion of assumptions and missing data sources). Surplus energy is calculated for an arbitrary future ore grade (based on five times the cumulative production from 1990 and the grade-tonnage relationship) assuming no efficiency increases. Methods in this subcategory include the Eco-indicator 99 method (Goedkoop and Spriensma 2001), the IMPACT 2002+ method (Jolliet et al. 2003), and the Stepwise 2006 method (Weidema et al. 2007).

Ore grade-surplus cost method The assessment as implemented in ReCiPe 2008 (Goedkoop et al. 2013) evaluates grades and yields of all mines exploiting a particular deposit type in order to estimate marginal ore grade decline and assumes a constant cost in order to calculate surplus cost.

Cost only method The surplus cost potential (SCP) method (Vieira et al. 2016b; Vieira 2018) uses a similar line of thinking to the SOP method but it uses cost-tonnage instead of grade-tonnage relationships. Thus, this method is not related to ore grade decrease. Instead, it is based on the average gradient of cumulative cost-tonnage curves that are fitted to resource size and cost data from existing mines, and extrapolated to known mineral reserves or resources.

Average crustal concentration methods These methods, implemented in EPS 2000/2015 (Steen 1999, 2016) and 
thermodynamic rarity (Valero and Valero 2015), assume the mining of the average crustal concentration (of elements or minerals, respectively) and assess the corresponding energy or exergy costs.

Economics-only methods These methods can be distinguished from the other future efforts methods by not relating their modeling to future ore grades or future costs of mining activities. Instead, they are based on mineral resource prices and economics, directly modeling economic relationships. Although the future welfare loss (Huppertz et al. 2019) and the LIME2 $2_{\text {endpoint }}$ approach (Itsubo and Inaba 2012) both start from prices, they have differences. Since the economics-only methods are much less discussed in literature than other methods and internal discussions about their differences were more intense than for other methods, the two methods are described in more detail below.

The future welfare loss approach (De Caevel et al. 2012; Huppertz et al. 2019) takes its starting point in the recognition that a part of the future scarcity value of a resource is already included in the current price of the resource, more specifically as the economic rent. The rent is the net present value (NPV) of the expected future revenue from extracting the resource and can be estimated as the difference between the price and the extraction cost of the resource. Although a part of the future scarcity value of a resource is thus already included in the resource price, it is not the full future value, since the current rent is calculated with the market discount rate, which is higher than the social discount rate. The current rent is therefore lower than what it would be using the social discount rate. This lower rent also leads to a faster depletion of the resource than what is socially optimal, i.e., when applying the social discount rate. The future welfare loss is the difference between the rent calculated with the social discount rate and the rent calculated with the market discount rate. By using this as the indicator, the future welfare loss approach assesses the potential externality of missed rents due to current overconsumption.

The LIME2 ${ }_{\text {endpoint }}$ method is based on El Serafy's user cost (Itsubo and Inaba 2014). The basic idea behind the user cost concept is to generate a permanent income from earnings from the sale of finite resources (El Serafy 1989). In order to achieve this, a part of the earnings must be set aside as a capital investment to generate this permanent income. This part, also called the user cost, is the difference between earnings without capital investment and the permanent income. By using this as the indicator, the LIME2 $2_{\text {endpoint }}$ method assesses the potential externality of missed future income due to a hypothetical lacking investment of earnings from the sale of finite resources.

\subsection{Thermodynamic accounting methods}

Thermodynamic accounting methods quantify the cumulative exergy (or energy) used in a product system. The exergy of a system or resource is the maximum amount of useful work that can be obtained from this system or resource when it is brought to (thermodynamic) equilibrium with its environment, implying that an environment or reference state must be defined (Dewulf et al. 2008). For metals and minerals, exergy methods account for either (i) the difference in exergy of these resources compared with the reference state (CEENE and CExD methods); (ii) the exergy replacement cost, defined as the exergy that would be needed to extract a mineral from a theoretical state of the earth's crust, in which all mineral resources are completely dispersed (thermodynamic rarity method); or (iii) the solar energy demand for the natural processes that has led to the current ore grades of the extracted primary mineral resources (SED method).

The cumulative exergy extraction from the natural environment (CEENE) method (Dewulf et al. 2007; Alvarenga et al. 2013; Taelman et al. 2014) and the cumulative exergy demand (CExD) method (Bösch et al. 2007) both consider the approach proposed by Szargut et al. (1988), in which the natural environment is the reference state. Thus, they account for the cumulative extraction of exergy embedded in target mineral resources (e.g., copper) as the exergy difference between the mineral resource as found in nature (e.g., copper in the ore) and a defined reference state in the natural environment (as defined by Szargut et al. (1988)). In Szargut's approach, the reference state is represented by a reference compound that is considered the most probable product of the interaction of the element with other common compounds in the natural environment and that typically shows high chemical stability (e.g., $\mathrm{SiO}_{2}$ for $\mathrm{Si}$ ) (De Meester et al. 2006). Although both methods are based on the same approach, they have differences in operationalization (see Section 6).

The thermodynamic rarity method (Valero and Valero 2015) incorporates two aspects: exergy costs (EC) and exergy replacement costs (ERC). The first evaluates the exergy cost required to mine and beneficiate a given commodity with prevailing technologies, assuming current average concentrations of mineral deposits and is similar to inventory accounting. The second aspect relates to the fact that having minerals concentrated in ore bodies (and not dispersed throughout the crust) represents a "free bonus" provided by nature, which reduces the otherwise required energy costs of mining. The reduction of this bonus when mines are depleted is quantified as so-called exergy replacement costs (ERC). These are defined as the cumulative exergy that would be needed to reconcentrate a mineral from a completely dispersed state (denoted Thanatia) to the conditions of concentration and composition found in the original mines using prevailing technology. Hence, ERC can be seen as the ultimate future effort that society would need to put into play when all mineral deposits become depleted. In contrast to the Szargut approach, the thermodynamic rarity method does not include a reference state in the form of reference compounds, but rather uses the 
composition and the average concentration of the 294 most abundant minerals found in the earth's crust from which the concentration exergy is calculated (Valero et al. 2018).

The solar energy demand (SED) method (Rugani et al. 2011) is based on the emergy concept, whereby emergy is the amount of energy that was required across direct and indirect transformations to make a product or service (Odum 1996). The SED method estimates this total direct and indirect environmental work for minerals and metals, measured in equivalent solar energy units. For metals, this includes consideration of the global sedimentary cycle as well as mine concentrations, whereas minerals are assumed to be co-products of the global sedimentary cycle (Rugani et al. 2011, SI).

To summarize, CEENE and CExD consider the same impact mechanism, i.e., the exergy extraction assessed as the difference between a mineral resource as found in nature and a defined reference state in the natural environment. The ERC approach also considers an exergy difference, calculated as the exergy requirement to re-concentrate a mineral resource from a completely dispersed state to mine concentration. The SED method has yet another starting point and differentiates between minerals and metals.

\subsection{Supply risk methods}

Three supply risk methods based on the criticality concept have been developed in the context of LCA: The geopolitical supply risk (GeoPolRisk) method (Gemechu et al. 2016; Helbig et al. 2016a; Cimprich et al. 2017b), the economic scarcity potential (ESP) method (Schneider et al. 2014), and the integrated method to assess resource efficiency (ESSENZ) (Bach et al. 2016), which is an extension and update of the ESP method. The criticality concept typically includes considerations of potential supply disruption (e.g., due to trade barriers, armed conflicts, economic and technological limitations of exploration and extraction, environmental regulations, and natural disasters) and vulnerability to supply disruption (e.g., assessed by potential (socio-economic) impacts of this supply disruption), and it typically considers 10-year time horizons (defined within the task force as a short time horizon) (see e.g. Achzet and Helbig 2013; Graedel and Reck 2015). In accordance with classical risk theory, we refer to the three methods mentioned above as "supply risk methods", whereby supply risk is conceptualized as a function of supply disruption probability and vulnerability (Cimprich et al. 2019). Importantly, our conceptualization of "supply risk" deviates from the common use of this term in the criticality literature, which, as argued by Glöser et al. (2015) and Frenzel et al. (2017), refers to supply disruption probability only.

While supply risk assessment concerns potential "outsidein" impacts of supply disruptions on a given product system (for example, impaired product performance, increased production costs, and/or lost revenue due to production shutdowns), the characterization models of LCA traditionally concern "inside-out" impacts of a product system on the environment (e.g., climate change, acidification, and particulate matter formation) (Cimprich et al. 2019). Another key difference from "traditional" LCA characterization models is that, as the total supply risk associated with a product system is a function of its entire supply chain, supply risk is evaluated for both elementary flows and intermediate flows, which here are collectively termed "inventory flows" following (Cimprich et al. 2019).

The ESP method, along with the ESSENZ method that supersedes it, directly build upon criticality concepts and thereby include many factors relevant to supply disruption probability - for ESSENZ, these include mining capacity, primary material use, concentration of reserves and production, company concentration, price volatility, demand growth, feasibility of exploration projects, trade barriers, political stability, and co-production. The GeoPolRisk method, on the other hand, focuses more narrowly on geopolitical stability. Although the ESSENZ method includes other supply disruption probability factors besides political stability, the impact pathways for the other factors are conceptually similar to those for political stability. We therefore focus on this indicator for the purpose of describing and comparing the GeoPolRisk and ESSENZ methods. Supply disruption probability depends on the geopolitical stability of countries from which inventory flows are sourced. To measure political stability, all three methods apply a different set of the Worldwide Governance Indicators (WGIs) published by the World Bank (2018). Supply disruption probability is also a function of mediating factors that influence the likelihood and severity of supply disruptions arising from political instability. All three methods use the production concentration, typically measured by the Herfindahl-Hirschman index (HHI), as a mediating factor. All else being equal, higher production concentration reduces the potential for supply-chain restructuring to mitigate supply disruptions and therefore increases supply risk. While the GeoPolRisk method weights the WGI values of upstream raw material-producing countries by their import shares to downstream product-manufacturing countries, the ESP and ESSENZ methods calculate a global average WGI index using country production shares of raw materials. Supply disruption vulnerability reflects the impacts of supply disruptions that may occur (Helbig et al. 2016b). Whereas the ESP and ESSENZ methods consider larger amounts of materials used in the considered product system to indicate higher vulnerability, the GeoPolRisk method considers all materials to be of equal importance regardless of the amounts in which they are used. An extension of the GeoPolRisk method by (Cimprich et al. 2017a) also considers substitutability of materials as a mediating factor for vulnerability. A more detailed review of the GeoPolRisk, ESP, and ESSENZ methods can be found in Cimprich et al. (2019). 


\section{Criteria-based assessment of methods}

All 27 methods were assessed by method developers and/or one to three other reviewers from the task force using a set of 45 mainly descriptive criteria grouped into seven main categories (see Supplementary Material 2). While the Life Cycle Initiative provided the seven main categories, the mineral resource-specific sub-criteria were developed by the task force through an iterative process to arrive at a comprehensive assessment scheme. Here, we focus on those criteria that highlighted the differences between methods and therefore can be used to guide application-dependent use of the methods, while highlighting areas for further methodological development (see Berger et al. (2020)).

General characteristics Since the methods differ in the impacts intended to be assessed, their characterization factors have different units, even within method categories. Furthermore, the methods consider different time horizons (from a few years to hundreds of years). As discussed in previous sections, all "traditional" LCA methods have an inside-out perspective whereas supply risk methods have been developed with an outside-in perspective.

Completeness of scope All methods have a global scope and no further geographical resolution, except for the GeoPolRisk, which is at the country level. With regard to the categorization into midpoint and endpoint methods, our result is consistent with existing literature (e.g., EC-JRC (2011)). Depletion and thermodynamic accounting methods are considered midpoint methods. Within future efforts methods, "ore grade only" methods (see Section 4.2) are considered midpoint methods, whereas the others are considered endpoint methods. The exception is the SOP method, which is considered a midpoint in ReCiPe 2016 and to be an endpoint in LC-Impact. This illustrates that within the midpoint and endpoint indicators, there is no general agreement yet on what the midpoint or the endpoint should be and the distinction between the two is not always obvious. Supply risk methods are considered midpoint methods.

Coverage of impact mechanisms and resources Our classification of methods reflects to some extent the (environmental) impact mechanisms considered; i.e., depletion methods consider depletion rates, thermodynamic accounting considers exergy extraction from nature, and supply risk methods assess supply disruption probability and vulnerability. With future efforts methods, this is less clear: By assessing (future) additional efforts needed to access mineral resources, they are implicitly also assessing aspects of depletion. Not all impact mechanisms considered are environmental. Those for the GeoPolRisk method for example are primarily socioeconomic and often there is a mixture of environmental and economic mechanisms as for example in the ADP methods. Existing methods have been designed for mineral resources and, except for the thermodynamic accounting methods, typically have limited, if any, coverage of other natural resources (e.g., water, land, biotic resources).

Peer review, data sources, and uncertainty Except for ReCiPe 2008, all methods were peer reviewed. Characterization factors based on stock estimates throughout the different methods often rely on data from the USGS, with original publication dates of the data differing widely from the 1990s to almost up to date. Eco-indicator 99 (and hence IMPACT 2002+ and Stepwise 2006, which are based on it) is based on nontransparent data sources (see Goedkoop and Spriensma (2001), p.78; for a discussion of assumptions and data sources).

Documentation, transparency, and reproducibility All methods are documented - although with varying levels of detail — and the underlying models and the input data needed are accessible in most cases. However, some of the documentation, models, and data are not accessible for free.

Applicability and ease of implementation All depletion and future efforts methods are compatible with existing Life Cycle Inventories (LCIs), which provide elementary flows in kilogram primary resource. Thermodynamic accounting methods are also compatible except for thermodynamic rarity. The supply risk methods are based on both elementary and intermediate flows and are therefore not yet fully compatible with "traditional" LCIs. The coverage of elementary flows varies widely from 9 to over 70 elementary flows, being 40 on average (for details, see Supplementary Material 2). The lack of characterization factors for rare earth metals has been highlighted for many methods, and mineral aggregates are rarely covered (only by eco-scarcity, SOP/SCP, and supply risk methods).

\section{Discussion of methods}

Some of the main points of contention, particularly in relation to depletion and future efforts methods, pertain to a broader discussion around resource depletion and scarcity-and whether these are real or perceived issues. Significant research efforts have been undertaken within the broader geoscience, sustainable development, mineral economics, and industrial ecology research communities to understand the complexities underpinning their assessment. These studies highlight the fluidity of mineral reserve and resource estimates (Meinert et al. 2016), the complexity and shortcomings of metrics such as ore grades for assessing resource depletion (West 2011; Priester et al. 2019), the general uncertainty over society's 
future mineral resource needs and the degree to which mineral exploration will be successful in meeting these (Ali et al. 2017), and the ultimate impact of this on commodity prices and policy requirements (Tilton et al. 2018).

The following subsections discuss each of our four method categories (depletion, future efforts, thermodynamic accounting, and supply risk) in more detail.

\subsection{Depletion methods}

The main points for discussion of depletion methods are the choice of stock estimate, the use of extraction to stock ratios or stocks only, and the inclusion of anthropogenic stocks.

While the "ultimately extractable reserves" is the relevant stock estimate in terms of depletion of the natural stock, it will never be exactly known because of its dependence on future technological developments (Guinée and Heijungs 1995) and unavoidable geologic uncertainty. Therefore, it can only be approximated and $\mathrm{ADP}_{\text {ultimate reserves }}$ is currently considered the best proxy according to the ADP developers (Guinée and Heijungs 1995; van Oers et al. 2002; van Oers and Guinée 2016). This recommendation is mainly based on the fact that estimates of economic reserves and the reserve base fluctuate over time as they are defined by economic considerations not directly related to the depletion problem, thus resulting in unstable and continuously changing estimates. However, the use of ultimate reserves has been criticized by geologists as inappropriate for the assessment of mineral resource availability because a majority of the material contained in the earth's crust may always remain unavailable for extraction (Drielsma et al. 2016a). The use of $\mathrm{ADP}_{\text {reserve base }}$ and $\mathrm{ADP}_{\text {economic re- }}$ serves has also been criticized as irrelevant to assess the relative rate of long-term depletion of the natural stock, since both are a function of the level of exploration undertaken, which is based on economic considerations (Drielsma et al. 2016b). They should be interpreted as a snapshot taken at a certain point in time that reflects a subset of the reserves currently available, so they imply a short to mid-term time horizon (up to a few decades). Therefore, they could rather be seen as an indicator for potential mineral resource availability issues related to mid-term (a few decades) physical-economic resource scarcity (see also Berger et al. 2020). Furthermore, as they vary in time, the characterization factors would need to be updated on a regular basis. Since the USGS no longer estimates the reserve base (USGS 2010), this is only possible for $\mathrm{ADP}_{\text {economic reserves }}$ (stock estimate and extraction rates) and $\mathrm{ADP}_{\text {ultimate reserves }}$ (extraction rates).

The inclusion of current annual extraction in the characterization model has advantages and disadvantages. On the one hand, the inclusion of extraction may lead to an underestimation of future risks of supply shortages for minerals that are not used in large volumes, as suggested by the developers of the LIME method. On the other hand, even the authors of the
LIME2 $2_{\text {midpoint }}$ method discuss extraction rates as a relevant factor, since they provide an indication for the risk of depletion. The definition of what constitutes the flow that renders mineral resources unavailable is often not explicitly stated in available methods. The extraction of mineral resources from nature to technosphere is usually approximated with production data, which refer to the net production of target metals rather than the overall quantities extracted from nature to technosphere (i.e., flows of material which end up in tailings, waste rock, or as emissions to nature are not accounted for). This is equal to the implicit assumption that the efficiency of concentrate production is similar for all metals and does not influence the relative results of the ADP indicator. This assumption may not hold in all cases, particularly for co- and byproduct commodities.

Recent conceptual developments of the ADP and the AADP method also consider anthropogenic stocks. Accordingly, the extraction from nature to technosphere is not considered to automatically render mineral resources inaccessible. It is rather the type of transformation and the destination of the mineral resource that determine whether it remains (potentially) useable. The depletion of the total stock (natural + anthropogenic) only happens if the mineral resource is emitted or diluted (terms used in van Oers et al. (2002)) or dissipated (term used in Stewart and Weidema (2005)) and remains unrecoverable. While the AADP characterization model includes the sum of the natural and the anthropogenic stocks in the denominator, the numerator only accounts for mineral resource extraction from natural stocks.

To summarize, the $\mathrm{ADP}_{\text {ultimate reserves }}$ may be considered the most suitable existing approach to assess the relative rate of long-term depletion of natural mineral stocks. As suggested by the method developers, ADP methods based on other stock estimates could be used for sensitivity analysis (van Oers et al. 2002) or they might be used with a different interpretation, as discussed above. In addition, other depletion methods, i.e.,

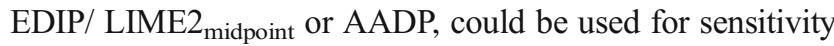
analysis. As described above, none of the existing methods fully reflects the issue of dissipation (for a more detailed discussion of the dissipation concept, see Berger et al. (2020)).

\subsection{Future efforts methods}

The main points for discussion of future efforts methods are the assumption of declining ore grades and the data upon which the different methods are based. The Economics-only methods, LIME2 $2_{\text {endpoint }}$ and future welfare loss, are discussed separately.

The main assumption of many future efforts methods is that preferential extraction of known higher-grade mineral resources will lead to long-term decline in the average mineral resource grade. This is an assumption for the long-run future and therefore impossible to prove or falsify. At first glance, it 
appears to be supported by an observed long-term (over the past century) trend of declining mined ore grades for a variety of (but not all) mineral commodities and regions (Crowson 2012; Mudd et al. 2013, 2017). However, there is confounding influence of technology, economic, and market conditions: when technology improves or when growth in demand exceeds growth in supply, a decline in mined ore grades would be expected, independent of mineral resource depletion considerations (West 2011; Northey et al. 2017). When supply capacity exceeds demand, mined ore grades have been observed to increase despite continued extraction (e.g., gold between 2014 and 2017). Furthermore, when demand triggers investments in exploration, deposits are typically found and code based (i.e., JORC, CRIRSCO, and NI43-101) mineral resources or reserves defined with grades profitable under the foreseeable economic situation. Currently, there are no studies that assess in detail how much these competing factors have contributed to historical ore grade changes. Therefore, the methods making use of the declining ore grade concept are effectively using correlations rather than seeking to identify causal factors of grade decline. Furthermore, the ore requirement indicator (ORI) and the surplus cost potential (SCP) methods base their indicators on observed ore grade decline or cost increase during a period with substantial growth in mineral demand as well as in costs and prices. The validity of their assumption of a causal relationship between consumption and ore grade decline or cost increase can therefore be questioned and the underlying data used should ideally be tested over multiple commodity price cycles. The ReCiPe2008 approach (based only on existing mines) and methods using grade-tonnage relationships based on data from existing mines and known deposits (ore grade decrease and surplus ore potential (SOP)) may be criticized for extrapolating data of known deposits to all potentially accessible deposits, including unknown deposits. As mentioned in Section 5, Eco-indicator 99 (and hence IMPACT 2002+ and Stepwise 2006, which are based on it) is based on nontransparent data sources (see Goedkoop and Spriensma 2001, p. 78). Furthermore, these methods assess the surplus energy consequences of extracting natural resources from lower-grade deposits at an arbitrarily chosen time horizon, i.e., when extraction reaches 5 times cumulated extraction before 1990. Similarly, EPS 2000/2015 and thermodynamic rarity consider extraction from a completely dispersed state of all elements and minerals, respectively. None of these methods models an ore grade decline (and its consequences) based on extraction data but only considers an assumed change in ore grades at a future point in time.

Among the ore grade methods, SOP has the most solid data foundation. The cumulative grade-tonnage distributions underpinning the method provide a physical basis for comparing the likely relative (but not absolute) impacts of mineral extraction, based upon current technical and economic supply capabilities.
The main weakness of SOP is that it is assuming mining from the highest to the lowest grade and not explicitly accounting for competing factors such as technology and economic considerations. Besides the discussion on decreasing ore grades, data on future mineral resources and technologies will of course always be inherently uncertain, and the different practical implementations of the future efforts methods will therefore always depend on different forecasts and assumptions.

Economics-only methods, i.e., future welfare loss and LIME $2_{\text {endpoint }}$, do not rely on a prediction of future ore grades or efforts and hence avoid the corresponding difficulties and uncertainties. Instead, they model (potential) economic externalities and thereby introduce relative (not absolute) uncertainties of discounting methods, i.e., uncertainties that affect all resources equally and therefore not their relative ranking. The future welfare loss and the LIME2 $2_{\text {endpoint }}$ methods can be seen as complementary, since they address two different economic externalities, namely that caused by the difference between the private and social discount rates (future welfare loss) and that caused by insufficient reinvestment of the economic rent (LIME2 endpoint). $_{\text {. }}$.

\subsection{Thermodynamic accounting methods}

Thermodynamic accounting methods do not explicitly link used amounts of mineral resources to changes in their availability. Furthermore, the thermodynamic rarity method does not yet provide CFs fitting to elementary flows in Life Cycle Inventory databases. However, thermodynamic accounting methods may be used in LCA as proxy for (overall) environmental impacts (like cumulative energy demand; Huijbregts et al. 2006, 2010; Steinmann et al. 2017) or for efficiency and renewability assessment as in Dewulf et al. (2005).

The CEENE method was developed with the aim of addressing some of the shortcomings of the CExD method, particularly with regard to land use and renewable energies (for a detailed discussion of the differences between the methods, see Dewulf et al. (2007)). With regard to mineral resources, CExD calculates the exergy of metals from the whole metal ore that enters the technosphere, whereas CEENE only regards the metal-containing minerals of the ore, with the argument that the tailings from the beneficiation are often not chemically altered when deposited (Dewulf et al. 2007). Furthermore, the CEENE method has been further improved and extended for land use (Alvarenga et al. 2013) and occupation of the marine environment (Taelman et al. 2014).

The thermodynamic rarity approach (particularly through the ERC concept) can be seen as assessing the geological and technological availability of mineral resources, assessed as the cumulative exergy that would be needed to re-concentrate a mineral from a completely dispersed state to the conditions of concentration and composition found in the original mines using prevailing technology. Therefore, it is related to the future efforts methods 
(see according sections) and-although it was not purposely developed to be incorporated into the LCA structure-is the closest in addressing the availability of mineral resources for human purposes of the thermodynamic accounting approaches. On the other hand, the ERC approach is also different, e.g., with regard to the reference state, which might be considered less mature than the one of Szargut. Furthermore, the underlying hypotheses and assumptions lack on clear cause-and-effect relationships (e.g., Thanatia as the final outcome of humankind, in the very long timeframe, and the need for re-concentration of dispersed metals with current technology). And finally, its role (thermodynamic accounting or future efforts or both?) and its integration into LCA still need to be clarified.

In case there is interest to consider the value of resources for beneficiaries other than humans as well, e.g., biota, or to consider the indirect value for humans (provided through the value for others, like natural ecosystem and their biotic elements), the SED might serve this purpose. Like emergy synthesis, SED looks at a system as embedded in the larger natural system that underpins it and includes all direct and indirect inputs to support it, independently of the actual usefulness of the ecological and technological inputs delivered to the systems under study (Raugei et al. 2014).

\subsection{Supply risk methods}

In comparison with the GeoPolRisk method, the ESP and ESSENZ methods serve different goals and scopes: whereas the latter two aim to provide characterization factors with global applicability - much like "traditional" LCIA mineral resource impact assessment methods - the GeoPolRisk method aims to highlight differences in supply risk between countries based on trading relationships. Accordingly, the ESP method and the ESSENZ method may be used for calculating global average supply risk characterization factors that can be applied by multinational companies having locations all over the world. The GeoPolRisk method, on the other hand, may be used for country-level supply risk assessment. Since the short-term and outside-in-perspectives of supply risk methods are different from those of "traditional" LCIA methods, there have been intense discussions without consensus in the task force about whether they should be seen as (i) being clearly outside of LCA, (ii) being complementary (e.g., as part of a broader life cycle sustainability assessment (LCSA) framework (Schneider et al. 2014; Sonnemann et al. 2015)), or (iii) even being another part of LCA (see also Berger et al. (2020)). A more detailed discussion of the three methods can be found in Cimprich et al. (2019).

\section{Conclusions}

Twenty-seven LCIA methods assessing impacts of mineral resource use were thoroughly reviewed. The methods were categorized based on modeled impact mechanisms and assessed using an extensive set of criteria. The concepts underlying the method categories and the individual methods were described, compared, and discussed. Of the four main method categories (Fig. 2), we consider depletion and future efforts methods more "traditional" LCIA methods, whereas thermodynamic accounting and supply risk methods are rather providing complementary information that might be useful for more encompassing life cycle approaches.

Of the depletion methods, $\mathrm{ADP}_{\text {ultimate reserves }}$ provides the most constant assessment of the relative potential of long-term depletion of natural stocks of mineral resources since crustal content estimates have been quite stable over time. Other variations of the ADP method might be used for sensitivity analysis or with a different interpretation. For example, $\mathrm{ADP}_{\text {economic reserves }}$ could be used to assess potential resource availability issues related to mid-term (a few decades) physico-economic resource scarcity. New conceptual developments - further discussed in Berger et al. (2020) strive towards a "dissipation" approach by including the anthropogenic stock and dissipation flows in the modeling.

Ore grade-related future efforts methods often assume that mining takes place from the highest to the lowest grade although different ore grades are mined in parallel. Furthermore, they do not explicitly account for competing factors such as technology and economic considerations. Therefore, further studies would be needed to confirm that the assumptions behind the ore grade-related future efforts methods are nonetheless valid in the long run. Among these methods, SOP has the most solid data foundation. The ORI and the SCP methods rely on empirical data from a period with substantial growth in mineral demand and prices, which is one reason why their assumption of a causal relationship can be questioned. The underlying data should ideally be tested over multiple commodity price cycles to validate the assumed relationships. Some approaches need more discussion because they consider other aspects or have not been discussed extensively before. One of these approaches is the exergy replacement costs (ERC) as implemented in thermodynamic rarity, which provides a different measurement for ore quality than the other ore grade approaches. Another group of methods is the economics-only methods. They use market prices instead of using physical data on future ore grades, technologies, and supply-demand relationships. Thereby, they consider market agents to have privileged access to information on aspects like future applications of the resource, future backstop technologies, recycling potentials, the evolution of reserves, and extraction costs, so that all these aspects will be taken into account in the market price (Huppertz et al. 2019). In this way, the uncertainty of the economic information includes the markets' assessment of the uncertainty of the physical information.

The thermodynamic accounting methods include three different approaches. CEENE and CExD calculate the exergy 
difference between the mineral resource as found in nature (e.g., copper in the ore) and a reference compound in the natural environment. The CEENE method has been developed to address some shortcomings of the CExD method. The ERC approach includes the aspect of concentrations in mines and considers minerals instead of reference compounds. It is thereby similar to CEENE and CExD (by assessing a difference in exergy) but it also contains elements of future efforts methods (by considering mineral resource quality in mines). However, the approach still needs to be integrated into the LCA structure as no characterization factors compatible with LCI databases are available yet. Finally, the SED method estimates the total direct and indirect solar energy requirement to concentrate the mineral resource to its current state.

The supply risk methods have an "outside-in" perspective compared with the "traditional" LCIA methods with their "inside-out" perspective, thus complementing environmental LCA with a socio-economic risk perspective (see also Berger et al. (2020)). There was no agreement in the task force whether they are in the scope of LCA or only part of LCSA. In any case, some practitioners might be interested in the shortterm and outside-in-perspectives of these methods.

Based on the insights from this thorough review and assessment of existing methods, recommendations for applicationdependent use of existing methods along with areas for further methodological development have been developed in a Pellston Workshop ${ }^{\circledR}$, a report of which is presented in the second part of this paper series (Berger et al. 2020).

Acknowledgments We thank the other task force members for their participation in the process and their valuable inputs to discussions. Special thanks goes to Marisa Vieira (PRé Consultants) for providing her expertise as a method developer, to Andrea Thorenz (University of Augsburg) for supporting the supply risk discussions, and to Johannes Drielsma (Euromines) for valuable discussions and comments on the manuscript. This work was supported by the Life Cycle Initiative hosted by the UN Environment.

\section{Compliance with ethical standards}

Disclaimer The views, interpretations and conclusions presented in this paper are those of the authors and do not necessarily reflect those of their respective organizations.

\section{References}

Achzet B, Helbig C (2013) How to evaluate raw material supply risksan overview. Res Policy 38:435-447. https://doi.org/10.1016/j. resourpol.2013.06.003

Ali SH, Giurco D, Arndt N, Nickless E, Brown G, Demetriades A, Durrheim R, Enriquez MA, Kinnaird J, Littleboy A, Meinert LD, Oberhänsli R, Salem J, Schodde R, Schneider G, Vidal O, Yakovleva N (2017) Mineral supply for sustainable development requires resource governance. Nature 543:367-372. https://doi.org/ 10.1038 /nature21359
Alvarenga RAF, Dewulf J, Van Langenhove H, Huijbregts MAJ (2013) Exergy-based accounting for land as a natural resource in life cycle assessment. Int J Life Cycle Assess 18:939-947. https://doi.org/10. 1007/s11367-013-0555-7

Bach V, Berger M, Henßler M et al (2016) Integrated method to assess resource efficiency - ESSENZ. J Clean Prod 137:118-130. https:// doi.org/10.1016/j.jclepro.2016.07.077

Berger M, Sonderegger T, Alvarenga R et al (2020) Mineral resources in life cycle impact assessment - part II: recommendations on application-dependent use of existing methods and on future method development. Int J Life Cycle Assess. https://doi.org/10.1007/ s11367-020-01737-5

Bösch ME, Hellweg S, Huijbregts MAJ, Frischknecht R (2007) Applying cumulative exergy demand (CExD) indicators to the ecoinvent database. Int J Life Cycle Assess 12:181-190. https://doi.org/10.1065/ lca2006.11.282

Cimprich A, Bach V, Helbig C et al (2019) Raw material criticality assessment as a complement to environmental life cycle assessment: examining methods for product-level supply risk assessment. J Ind Ecol:1-11. https://doi.org/10.1111/jiec.12865

Cimprich A, Karim KS, Young SB (2017a) Extending the geopolitical supply risk method: material "substitutability" indicators applied to electric vehicles and dental x-ray equipment. Int J Life Cycle Assess 23:2024-2042. https://doi.org/10.1007/s11367-017-1418-4

Cimprich A, Young SB, Helbig C et al (2017b) Extension of geopolitical supply risk methodology: characterization model applied to conventional and electric vehicles. J Clean Prod 162:754-763. https://doi. org/10.1016/j.jclepro.2017.06.063

Crowson P (2012) Some observations on copper yields and ore grades. Res Policy 37:59-72. https://doi.org/10.1016/j.resourpol.2011.12. 004

De Caevel B, Standaert S, Van Overbeke E (2012) How to correct price for monetising non-renewable resource consumption? In: SETAC Europe 22nd annual meeting - extended abstracts, Berlin

De Meester B, Dewulf J, Janssens A, Van Langenhove H (2006) An improved calculation of the exergy of natural resources for Exergetic Life Cycle Assessment (ELCA). Environ Sci Technol 40:6844-6851. https://doi.org/10.1021/es060167d

Dewulf J, Benini L, Mancini L, Sala S, Blengini GA, Ardente F, Recchioni M, Maes J, Pant R, Pennington D (2015) Rethinking the area of protection "natural resources" in life cycle assessment. Environ Sci Technol 49:5310-5317. https://doi.org/10.1021/acs.est. 5 b00734

Dewulf J, Boesch ME, De Meester B et al (2007) Cumulative exergy extraction from the natural environment (CEENE): a comprehensive life cycle impact assessment method for resource accounting. Environ Sci Technol 41:8477-8483. https://doi.org/10.1021/ es0711415

Dewulf J, Van Langenhove H, Muys B et al (2008) Exergy : its potential and limitations in environmental science and technology. Environ Sci Technol 42:2221-2232. https://doi.org/10.1021/es071719a

Dewulf J, Van Langenhove H, Van De Velde B (2005) Exergy-based efficiency and renewability assessment of biofuel production. Environ Sci Technol 39:3878-3882. https://doi.org/10.1021/ es $048721 \mathrm{~b}$

Drielsma JA, Allington R, Brady T et al (2016a) Abiotic raw-materials in life cycle impact assessments: an emerging consensus across disciplines. Resources 5:12. https://doi.org/10.3390/resources5010012

Drielsma JA, Russell-Vaccari AJ, Drnek T et al (2016b) Mineral resources in life cycle impact assessment — defining the path forward. Int J Life Cycle Assess 21:85-105. https://doi.org/10.1007/s11367015-0991-7

EC-JRC (2011) International Reference Life Cycle Data System (ILCD) Handbook: Recommendations for life cycle impact assessment in the European context. European Commission, Joint Research Centre, Institute for Environment and Sustainability, Ispra 
El Serafy S (1989) The proper calculation of income from Depletable natural resources. In: Environmental Accounting for Sustainable Development. The International Bank for Reconstruction and Development, The World Bank, Washington, D.C

Fraunhofer (2018) Science meets business workshop, march 6, 2018. Germany, Stuttgart

Frenzel M, Kullik J, Reuter MA, Gutzmer J (2017) Raw material ' criticality '- sense or nonsense ? J Phys D Appl Phys 50. https://doi. org/10.1088/1361-6463/aa5b64

Frischknecht R, Büsser Knöpfel S (2013) Swiss eco-factors 2013 according to the ecological scarcity method. Federal Office for the Environment FOEN, Bern

Gemechu ED, Helbig C, Sonnemann G et al (2016) Import-based indicator for the geopolitical supply risk of raw materials in life cycle sustainability assessments. J Ind Ecol 20:154-165. https://doi.org/ 10.1111/jiec. 12279

Glöser S, Tercero Espinoza L, Gandenberger C, Faulstich M (2015) Raw material criticality in the context of classical risk assessment. Res Policy 44:35-46. https://doi.org/10.1016/j.resourpol.2014.12.003

Goedkoop M, Heijungs R, de Schryver A et al (2013) ReCiPe 2008. A LCIA method which comprises harmonised category indicators at the midpoint and the endpoint level. Characterisation. Ministerie van VROM, Den Haag

Goedkoop M, Spriensma R (2001) The eco-indicator 99 - a damage oriented method for life cycle impact assessment. Amersfoort, The Netherlands

Graedel TE, Reck BK (2015) Six years of criticality assessments what have we learned so far? J Ind Ecol 20:692-699. https://doi.org/10. 1111 /jiec. 12305

Guinée JB, Heijungs R (1995) A proposal for the definition of resource equivalency factors for use in product life-cycle assessment. Environ Toxicol Chem 14:917-925. https://doi.org/10.1002/etc.5620140525

Hauschild M, Potting J (2005) Spatial differentiation in Life Cycle impact assessment - the EDIP2003 methodology. Environmental news No. 80. Danish Environmental Protection Agency, Copenhagen

Hauschild M, Wenzel H (1998) Environmental assessment of products volume 2: scientific background. Springer US

Helbig C, Gemechu ED, Pillain B et al (2016a) Extending the geopolitical supply risk indicator: application of life cycle sustainability assessment to the petrochemical supply chain of polyacrylonitrile-based carbon fibers. J Clean Prod 137:1170-1178. https://doi.org/10.1016/ j.jclepro.2016.07.214

Helbig C, Wietschel L, Thorenz A, Tuma A (2016b) How to evaluate raw material vulnerability - an overview. Res Policy 48:13-24. https:// doi.org/10.1016/j.resourpol.2016.02.003

Huijbregts MAJ, Hellweg S, Frischknecht R, Hendriks HW, Hungerbühler K, Hendriks AJ (2010) Cumulative energy demand as predictor for the environmental burden of commodity production. Environ Sci Technol 44:2189-2196. https://doi.org/10.1021/ es902870s

Huijbregts MAJ, Rombouts LJA, Hellweg S, Frischknecht R, Hendriks AJ, van de Meent D, Ragas AM, Reijnders L, Struijs J (2006) Is cumulative fossil energy demand a useful indicator for the environmental performance of products? Environ Sci Technol 40:641-648. https://doi.org/10.1021/es051689g

Huppertz T, Weidema BP, Standaert S et al (2019) The social cost of subsoil resource use. Resources 8. https://doi.org/10.3390/ resources 8010019

Itsubo N, Inaba A (2012) LIME 2 - life-cycle impact assessment method based on endpoint modeling - summary. JLCA Newsl Life-Cycle Assess Soc Japan 16. Available from: https://lca-forum.org/english/ pdf/No12_Summary.pdf. Accessed 12/12/2016

Itsubo N, Inaba A (2014) LIME2 - chapter 2 : characterization and damage evaluation methods. JLCA Newsl Life-Cycle Assess Soc Japan 18. Available from: https://lca-forum.org/english/pdf/No18 Chapter2.10-2.13.pdf. Accessed 17/08/2017
Jolliet O, Margni M, Charles R et al (2003) IMPACT $2002+$ : a new life cycle impact assessment methodology. Int J Life Cycle Assess 8: 324-330. https://doi.org/10.1007/BF02978505

Meinert LD, Jr GRR, Nassar NT (2016) Mineral resources : reserves. Peak Product Future. https://doi.org/10.3390/resources5010014

Mudd GM, Jowitt SM, Werner TT (2017) The world's by-product and critical metal resources part I: uncertainties, current reporting practices, implications and grounds for optimism. Ore Geol Rev 86:924938. https://doi.org/10.1016/j.oregeorev.2016.05.001

Mudd GM, Weng Z, Jowitt SM (2013) A detailed assessment of global cu resource trends and endowments. Econ Geol 108:1163-1183. https://doi.org/10.2113/econgeo.108.5.1163

Müller-Wenk R (1998) Depletion of abiotic resources weighted on the base of 'virtual' impacts of lower grade deposits in future. IWO Diskussionsbeitrag Nr. 57. Universität St. Gallen, St. Gallen

Northey SA, Mudd GM, Werner TT et al (2017) The exposure of global base metal resources to water criticality, scarcity and climate change. Glob Environ Chang 44:109-124. https://doi.org/10.1016/j. gloenvcha.2017.04.004

Nuss P, Eckelman MJ (2014) Life cycle assessment of metals: a scientific synthesis. PLoS One 9:1-12. https://doi.org/10.1371/journal.pone. 0101298

Odum HT (1996) Environmental accounting: emergy and environmental decision making. John Wiley \& Sons, Inc., New York

Priester M, Ericsson M, Dolega P, Löf O (2019) Mineral grades: an important indicator for environmental impact of mineral exploitation. Miner Econ 32:49-73. https://doi.org/10.1007/s13563-01800168-x

Raugei M, Rugani B, Benetto E, Ingwersen WW (2014) Integrating emergy into LCA: potential added value and lingering obstacles. Ecol Model 271:4-9. https://doi.org/10.1016/j.ecolmodel.2012.11. 025

Rørbech JT, Vadenbo C, Hellweg S, Astrup TF (2014) Impact assessment of abiotic resources in LCA: quantitative comparison of selected characterization models. Environ Sci Technol 48:11072-11081

Rugani B, Huijbregts MAJ, Mutel CL, Bastianoni S, Hellweg S (2011) Solar energy demand (SED) of commodity life cycles. Environ Sci Technol 45:5426-5433. https://doi.org/10.1021/es103537f

Schneider L, Berger M, Finkbeiner M (2011) The anthropogenic stock extended abiotic depletion potential (AADP) as a new parameterisation to model the depletion of abiotic resources. Int $\mathrm{J}$ Life Cycle Assess 16:929-936. https://doi.org/10.1007/s11367-0110313-7

Schneider L, Berger M, Finkbeiner M (2015) Abiotic resource depletion in LCA - background and update of the anthropogenic stock extended abiotic depletion potential (AADP) model. Int J Life Cycle Assess 20:709-721. https://doi.org/10.1007/s11367-015-0864-0

Schneider L, Berger M, Schüler-Hainsch E et al (2014) The economic resource scarcity potential (ESP) for evaluating resource use based on life cycle assessment. Int J Life Cycle Assess 19:601-610. https://doi.org/10.1007/s11367-013-0666-1

Sonderegger T, Dewulf J, Fantke P, Souza DM, Pfister S, Stoessel F, Verones F, Vieira M, Weidema B, Hellweg S (2017) Towards harmonizing natural resources as an area of protection in life cycle impact assessment. Int J Life Cycle Assess 22:1912-1927. https:// doi.org/10.1007/s11367-017-1297-8

Sonnemann G, Gemechu ED, Adibi N et al (2015) From a critical review to a conceptual framework for integrating the criticality of resources into life cycle sustainability assessment. J Clean Prod 94:20-34. https://doi.org/10.1016/j.jclepro.2015.01.082

Steen B (1999) A systematic approach to environmental priority strategies in product development (EPS). Version 2000 - general system characteristics. Centre for Environmental Assessment of Products and Material Systems (CPM). Chalmers University of Technology, Gothenburg 
Steen B (2016) Calculation of monetary values of environmental impacts from emissions and resource use the case of using the EPS 2015d impact assessment method. J Sustain Dev 9:15. https://doi.org/10. 5539/jsd.v9n6p15

Steen BA (2006) Abiotic resource depletion. Different perceptions of the problem with mineral deposits. Int J Life Cycle Assess 11:49-54. https://doi.org/10.1065/lca2006.04.011

Steinmann ZJN, Schipper AM, Hauck M, Giljum S, Wernet G, Huijbregts MAJ (2017) Resource footprints are good proxies of environmental damage. Environ Sci Technol 51:6360-6366. https://doi.org/10.1021/acs.est.7b00698

Stewart M, Weidema B (2005) A consistent framework for assessing the impacts from resource use: a focus on resource functionality. Int $\mathrm{J}$ Life Cycle Assess 10:240-247. https://doi.org/10.1065/lca2004.10. 184

Swart P, Alvarenga RAF, Dewulf J (2015) Abiotic resource use. In: Life cycle impact assessment. Springer, Dordrecht, pp 247-271

Swart P, Dewulf J (2013) Quantifying the impacts of primary metal resource use in life cycle assessment based on recent mining data. Resour Conserv Recycl 73:180-187. https://doi.org/10.1016/j. resconrec.2013.02.007

Szargut J, Morris DR, Steward FR (1988) Exergy analysis of thermal, chemical and metallurgical processes. Hemisphere Publishing, New York

Taelman SE, De Meester S, Schaubroeck T et al (2014) Accounting for the occupation of the marine environment as a natural resource in life cycle assessment: an exergy based approach. Resour Conserv Recycl 91:1-10. https://doi.org/10.1016/j.resconrec.2014.07.009

Tilton JE, Crowson PCF, DeYoung JH et al (2018) Public policy and future mineral supplies. Res Policy 57:55-60. https://doi.org/10. 1016/j.resourpol.2018.01.006

USGS (2010) Mineral Commodity Summaries 2010. US Geol Surv 196. https://oi.org/10.3133/70140094

Valero A, Valero A (2015) Thermodynamic rarity and the loss of mineral wealth. Energies 8:821-836. https://doi.org/10.3390/en8020821

Valero A, Valero A, Stanek W (2018) Assessing the exergy degradation of the natural capital: from Szargut's updated reference environment to the new thermoecological-cost methodology. Energy 163:11401149. https://doi.org/10.1016/j.energy.2018.08.091

van Oers L, Guinée J (2016) The abiotic depletion potential: background, updates, and future. Resources 5:16. https://doi.org/10.3390/ resources5010016

van Oers L, de Koning A, Guinée JB, et al (2002) Abiotic resource depletion in LCA. Improving characterisation factors for abiotic resource depletion as recommended in the new Dutch LCA Handbook. Road and Hydraulic Engineering Institute of the Dutch Ministry of Transport

Vieira MDM (2018) Fossil and mineral resource scarcity in life cycle assessment. Radboud University Nijmegen, the Netherlands

Vieira MDM, Goedkoop MJ, Storm P, Huijbregts MAJ (2012) Ore grade decrease as life cycle impact indicator for metal scarcity: the case of copper. Environ Sci Technol 46:12772-12778. https://doi.org/10. 1021/es302721t

Vieira MDM, Ponsioen TC, Goedkoop MJ, Huijbregts MAJ (2016a) Surplus ore potential as a scarcity indicator for resource extraction. J Ind Ecol. https://doi.org/10.1111/jiec.12444

Vieira MDM, Ponsioen TC, Goedkoop MJ, Huijbregts MAJ (2016b) Surplus cost potential as a life cycle impact indicator for metal extraction. Resources 5:2. https://doi.org/10.3390/resources5010002

Weidema BP, Hauschild MZ, Jolliet O (2007) Preparing characterisation methods for endpoint impact assessment. Available from lca-net. com/files/Stepwise2006v1.5.3.zip. Accessed 12 Dec 2016

Wenzel H, Hauschild MZ, Alting L (1997) Environmental assessment of products. Volume 1 - methodology, tools and case studies in product development. Kluwer Academic Publishers, Hingham, pp 544

West J (2011) Decreasing metal ore grades: are they really being driven by the depletion of high-grade deposits? J Ind Ecol 15:165-168. https://doi.org/10.1111/j.1530-9290.2011.00334.x

World Bank (2018) The Worldwide Governance Indicators. http://info. worldbank.org/governance/wgi/index.aspx\#home. Accessed 16 Nov 2018

Publisher's note Springer Nature remains neutral with regard to jurisdictional claims in published maps and institutional affiliations. 